\title{
Report on laboratory tests of sandstone and porphyry for rock fracture analysis
}

\author{
Jakub Gontarz ${ }^{1}$, Jacek Szulej ${ }^{2}$ \\ ${ }^{1}$ Department of Structural Mechanics; Faculty of Civil Engineering; Lublin University of Technology; \\ Nadbystrzycka St. 40, 20-618 Lublin, Poland; \\ j.gontarz@pollub.pl@0000-0002-6900-6158 \\ ${ }^{2}$ Department of Structural Mechanics; Faculty of Civil Engineering; Lublin University of Technology; \\ Nadbystrzycka St. 40, 20-618 Lublin, Poland; \\ j.szulej@pollub.pl (D)0000-0003-4745-7705
}

Funding: This research was sponsored by the Lublin University of Technology Science Financing Subsidy FN16/ILT/2020

Abstract: The paper presents the results of mechanical tests of three types of rocks from Polish stone mines. Compression tests of cubic samples, three-point bending tests of beams, bending of beams with a notch, and testing of tensile strength using the quasi-Brazilian method were performed. Based on the tests, the compressive strength, tensile strength, Young's modulus, and Poisson's ratios were determined. The stress intensity factor and critical strain energy release rate in mode I were determined from the bending test of the notched beams. The determined values were used as parameters of computer models, which allowed to verify the authors' method of predicting the crack propagation in the Abaqus FEA system.

Keywords: sandstone, porphyry, laboratory tests, fracture mechanics

\section{Introduction}

In this research, a series of laboratory tests on two types of sandstone and one type of porphyry were performed. The purpose was to obtain rock material parameters, based on which the authors would develop own method of determining the direction of crack propagation of brittle materials, such as rocks, in the Abaqus FEA system using the X-FEM method. Extended Finite Element Method is a method of simulating fracture that does not depend on the elements' mesh. Elements can break anywhere - this is allowed by the appropriate modification of the shape function. The authors used the Abaqus User Subroutine, a tool that is provided by Abaqus, to modify the calculation procedure. The description of own subroutine and the results of these analyzes will be published in the future. To properly verify the created method, several laboratory tests had to be performed. The paper 
presents the procedures and test results for required rock mechanical parameters. The tests described here are not innovative, however obtaining material parameters is necessary to verify computer analyzes. The authors also hope that the results presented in this work will help other scientists in their future research.

The choice of rock material was determined by the author's previous analysis [1], where the maximum force of pulling out the anchor from rocks mentioned above was investigated. New mining rescue technology without the use of explosives was initially developed in research commissioned by the KOMAG Institute of Mining Technology. A scheme of this study was presented in the author's previous paper [2], which also contains a summary of similar laboratory tests of different types of rocks. Some of the material parameters for the selected sandstone types (for example - "Brenna" sandstone) were described in work [3] by Tomiczek and [4] by Łukasiak. The analysis of the microstructure of sandstone is especially interesting. Finally, an example of research dealing with a similar subject to this one is [5], where the well-known "Szydłowiec" sandstone was studied.

\section{Description of materials and selection of tests}

Three types of rocks were tested: grey-coloured sandstone from the "Braciszów" mine, light or pink porphyry from the "Zalas" mine, and sandstone from the "Brenna" mine, similar to the "Braciszów" sandstone.

In the Abaqus system, selected mechanical parameters are required to simulate the crack using the simplest criterion for maximum principal stresses. Values of Young's modulus and Poisson's ratio are required, for elastic materials to which rocks belong, regardless of the cracking criterion. Therefore, cube compression tests were performed with the measurement of horizontal and vertical strain to obtain these parameters. To simulate the fracture in Abaqus, it is required to provide the stress at which the crack will occur. In the simplest case, this stress value is equivalent to the tensile strength. Therefore, three-point bending tests and a quasi-Brazilian test, i.e. tensile force during splitting cubic samples, were performed. Also, the beams were examined using the same quasi-Brazilian method, and the results were compared to the cubes. The analysis also requires providing critical strain energy release rate in mode I. The authors determined the stress intensity factor in mode I $K_{\text {IC }}$ through a three-point bending test of beams with notches. Compressive strength using cubes was also tested.

\section{Description of the mechanical parameters tests}

\subsection{Compression test of cubic samples}

The authors performed uniaxial compression tests for all described materials. 14 cubic samples of "Braciszów" sandstone (samples K1c-K14c), 10 samples of "Zalas" porphyry (K1z-K10z), and 12 samples of "Brenna" sandstone (K1b-K12b) were tested. For various reasons, the results of not all samples were used to calculate Young's modulus and Poisson's ratio. Samples of "Braciszów" sandstone and porphyry were about $7 \times 7 \times 7 \mathrm{~cm}$, and samples of "Brenna" sandstone were about $10 \times 10 \times 10 \mathrm{~cm}$. Unfortunately, the samples had irregular dimensions, because most of them were obtained from small fragments of cones obtained during the anchor pull-out test.

The samples were initially tested on the MTS 319.25 testing machine, with the measurement of vertical and horizontal deformations. The "Braciszów" sandstone and "Zalas" porphyry 
were tested first. Vertical displacements in one direction were determined using a displacement transducer (fig. 2a), measuring the change in sample height during the test. Horizontal displacements (perpendicular to the direction of the compressive force) were measured with a clip-on extensometer measuring the change in distance between the steel plates adhered to the samples. This test was carried out using low force to avoid destruction of the samples and measuring instruments. Then, after removing the measuring devices, the samples were loaded for destruction on a WalterBai testing machine.

It turned out that measuring only two displacements is insufficient to obtain accurate results. For this reason, the next samples from the "Brenna" sandstone were tested using strain gauges. Two vertical and two horizontal strain gauges were glued on opposite sides (fig. 1a, fig. 2b). Changes in displacement in both directions were determined as the arithmetic mean of the strain gauge pair.

a)

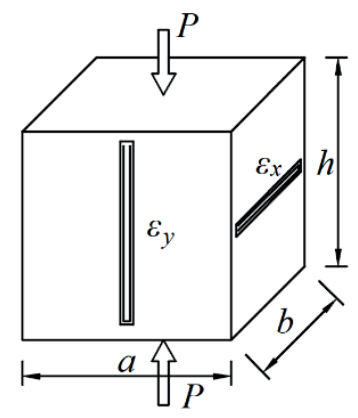

b)

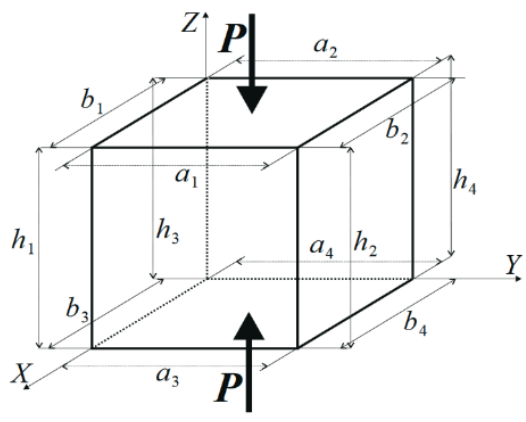

Fig. 1. Cubic sample. a) assembly method of strain gauges, b) sample dimensions: $a=\left(a_{1}+a_{2}+a_{3}+a_{4}\right) / 4$, $b=\left(b_{1}+b_{2}+b_{3}+b_{4}\right) / 4, h=\left(h_{1}+h_{2}+h_{3}+h_{4}\right) / 4$. Source: own study

The dimensions of the samples were determined as the average of the length of each of the four edges of a given dimension. Sample photos from the tests are shown in fig. 2.

a)

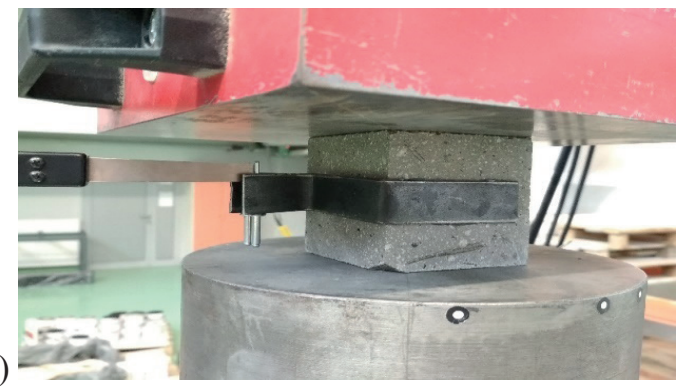

b)

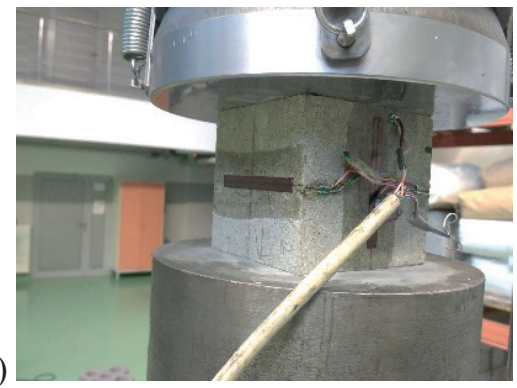

Fig. 2. Compression test of cubic samples. a) test of "Braciszów" sandstone with the extensometer and displacement transducer, b) test of "Brenna" sandstone with strain gauges. Source: own study

In Table 1, Table 2 and Table $3 a, b, h$-averaged dimensions of samples in accordance with fig. 1, $A$ - cross-sectional area of the sample: $A=a \times b, P$ - maximum force registered by the MTS system, $f_{\mathrm{c}}$ - compressive strength calculated based on the formula: $f_{\mathrm{c}}=P / A$, $E$ - Young's modulus, $v$ - Poisson's ratio determined according to the procedure described later. 
Table 1. Dimensions of the samples and results obtained in the uniaxial compression test for "Braciszów" sandstone. Source: own study

\begin{tabular}{llllllllll}
\hline \multirow{2}{*}{ Sample } & $\begin{array}{l}h \\
{[\mathrm{~mm}]}\end{array}$ & $\begin{array}{l}a \\
{[\mathrm{~mm}]}\end{array}$ & $\begin{array}{l}b \\
{[\mathrm{~mm}]}\end{array}$ & $\begin{array}{l}A \\
{\left[\mathrm{~cm}^{2}\right]}\end{array}$ & $\begin{array}{l}P \\
{[\mathrm{kN}]}\end{array}$ & $\begin{array}{l}f_{\mathrm{c}} \\
{[\mathrm{MPa}]}\end{array}$ & $\begin{array}{l}\lambda \\
{[\mathrm{kN} / \mathrm{mm}]}\end{array}$ & $\begin{array}{l}E \\
{[\mathrm{GPa}]}\end{array}$ & $\begin{array}{l}v \\
{[-]}\end{array}$ \\
\hline K1c & 69.54 & 69.70 & 70.19 & 48.92 & 922.6 & 188.604 & - & - & - \\
\hline K2c & 69.60 & 69.64 & 69.56 & 48.44 & 986.7 & 203.703 & 1080.05 & 15.519 & 0.208 \\
\hline K3c & 68.01 & 69.86 & 69.73 & 48.71 & 813.5 & 166.997 & 1189.51 & 16.606 & 0.205 \\
\hline K4c & 69.78 & 69.69 & 69.67 & 48.55 & 1025.2 & 211.166 & 705.23 & 10.136 & 0.120 \\
\hline K5c & 69.86 & 69.68 & 69.63 & 48.52 & 1081.8 & 222.960 & - & - & - \\
\hline K6c & 69.81 & 69.80 & 69.84 & 48.74 & 1087.6 & 223.137 & 1052.79 & 15.078 & 0.130 \\
\hline K7c & 69.76 & 69.74 & 69.83 & 48.70 & 974.1 & 200.037 & 987.82 & 14.150 & 0.291 \\
\hline K8c & 69.78 & 70.03 & 69.74 & 48.84 & 1001.5 & 205.069 & 1733.37 & 24.768 & - \\
\hline K9c & 69.92 & 69.95 & 69.99 & 48.96 & 968.1 & 197.741 & 1353.51 & 19.331 & 0.261 \\
\hline K10c & 70.11 & 70.06 & 69.88 & 48.95 & 1002.7 & 204.823 & - & - & - \\
\hline K11c & 87.57 & 86.86 & 87.47 & 75.97 & 1069.0 & 140.706 & - & - & - \\
\hline K12c & 86.40 & 84.61 & 86.89 & 73.52 & 1096.7 & 149.171 & - & - & - \\
\hline K13c & 86.18 & 87.34 & 84.63 & 73.91 & 1326.6 & 179.490 & 889.49 & 10.371 & - \\
\hline K14c & 87.14 & 86.90 & 87.84 & 76.33 & 974.3 & 127.645 & - & - & - \\
\hline & & & & & & & & & \\
\hline
\end{tabular}

a)

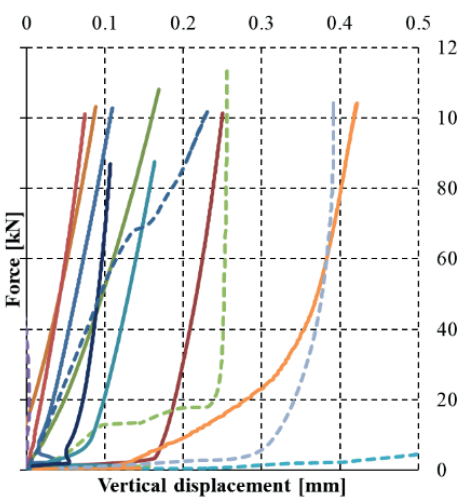

Vertical displacement [mm]

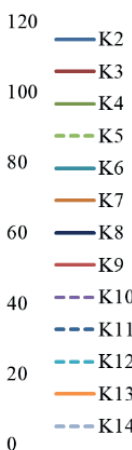

b)

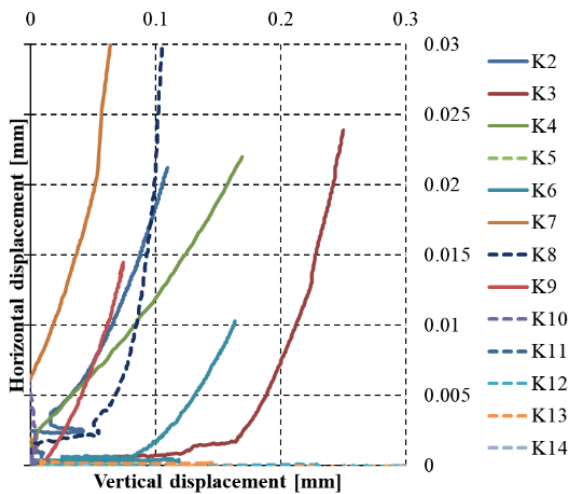

Vertical displacement [mm]

Fig. 3. Graphs of the uniaxial compression test for "Braciszów" sandstone: a) the relationship of force and vertical displacement, b) the relationship of horizontal and vertical displacement. Source: own study

Table 2. Dimensions of the samples and results obtained in the uniaxial compression test for "Zalas" porphyry. Source: own study

\begin{tabular}{llllllllll}
\hline \multirow{2}{*}{ Sample } & $\begin{array}{l}h \\
{[\mathrm{~mm}]}\end{array}$ & $\begin{array}{l}a \\
{[\mathrm{~mm}]}\end{array}$ & $\begin{array}{l}b \\
{[\mathrm{~mm}]}\end{array}$ & $\begin{array}{l}A \\
{\left[\mathrm{~cm}^{2}\right]}\end{array}$ & $\begin{array}{l}P \\
{[\mathrm{kN}]}\end{array}$ & $\begin{array}{l}f_{\mathrm{c}} \\
{[\mathrm{MPa}]}\end{array}$ & $\begin{array}{l}\lambda \\
{[\mathrm{kN} / \mathrm{mm}]}\end{array}$ & $\begin{array}{l}E \\
{[\mathrm{GPa}]}\end{array}$ & $\begin{array}{l}\nu \\
{[-]}\end{array}$ \\
\hline $\mathrm{K} 1 \mathrm{z}$ & 70.53 & 70.17 & 70.16 & 48.92 & 1047.3 & 212.738 & 883.70 & 12.661 & - \\
\hline $\mathrm{K} 2 \mathrm{z}$ & 70.19 & 70.31 & 70.20 & 48.44 & 980.5 & 198.673 & 830.82 & 11.816 & - \\
\hline $\mathrm{K} 3 \mathrm{z}$ & 69.98 & 69.88 & 70.06 & 48.71 & 839.6 & 171.500 & 684.55 & 9.786 & - \\
\hline $\mathrm{K} 4 \mathrm{z}$ & 70.10 & 70.60 & 69.95 & 48.55 & 1185.5 & 240.046 & - & - & - \\
\hline $\mathrm{K} 5 \mathrm{z}$ & 70.17 & 70.32 & 70.12 & 48.52 & 1160.7 & 235.379 & 1260.10 & 17.937 & - \\
\hline $\mathrm{K} 6 \mathrm{z}$ & 70.61 & 70.05 & 70.06 & 48.74 & 988.7 & 201.444 & 580.58 & 8.353 & - \\
\hline $\mathrm{K} 7 \mathrm{z}$ & 70.37 & 70.33 & 70.09 & 48.70 & 752.9 & 152.741 & 872.36 & 12.453 & - \\
\hline $\mathrm{K} 8 \mathrm{z}$ & 70.06 & 70.23 & 70.00 & 48.84 & 1328.2 & 270.183 & 1115.48 & 15.897 & - \\
\hline $\mathrm{K} 9 \mathrm{z}$ & 69.90 & 69.79 & 69.90 & 48.96 & 904.7 & 185.440 & 977.65 & 14.008 & - \\
\hline $\mathrm{K} 10 \mathrm{z}$ & 70.26 & 69.74 & 70.13 & 48.95 & 935.4 & 191.254 & - & - & - \\
\hline & & & & & & & & & \\
\hline
\end{tabular}



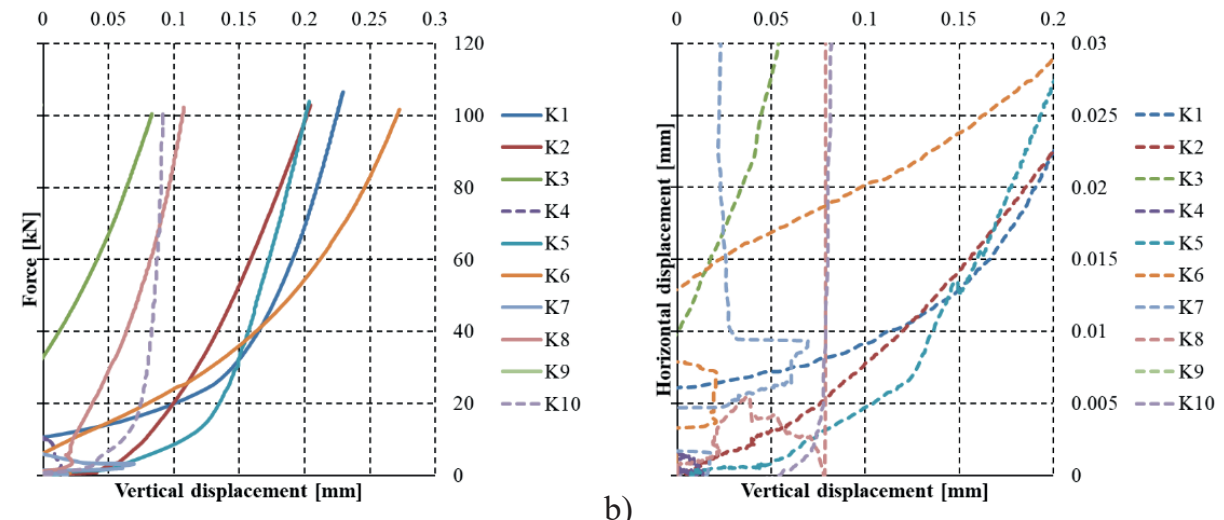

Fig. 4. Graphs of the uniaxial compression test for "Zalas" porphyry: a) the relationship of force and vertical displacement, b) the relationship of horizontal and vertical displacement. Source: own study

Table 3. Dimensions of the samples and results obtained in the uniaxial compression test for "Brenna" sandstone. Source: own study

\begin{tabular}{llllllllll}
\hline Sample & $\begin{array}{l}h \\
{[\mathrm{~mm}]}\end{array}$ & $\begin{array}{l}a \\
{[\mathrm{~mm}]}\end{array}$ & $\begin{array}{l}b \\
{[\mathrm{~mm}]}\end{array}$ & $\begin{array}{l}A \\
{\left[\mathrm{~cm}^{2}\right]}\end{array}$ & $\begin{array}{l}P \\
{[\mathrm{kN}]}\end{array}$ & $\begin{array}{l}f_{\mathrm{c}} \\
{[\mathrm{MPa}]}\end{array}$ & $\begin{array}{l}\lambda \\
{[\mathrm{kN} / \mathrm{mm}]}\end{array}$ & $\begin{array}{l}E \\
{[\mathrm{GPa}]}\end{array}$ & $\begin{array}{l}v \\
{[-]}\end{array}$ \\
\hline K1b & 95.25 & 89.95 & 89.08 & 80.12 & - & - & 1087.35 & 12.927 & 0.188 \\
\hline K2b & 89.40 & 89.47 & 87.34 & 78.15 & - & - & 1027.62 & 11.756 & - \\
\hline K3b & 89.81 & 92.98 & 87.18 & 81.06 & - & - & 1560.06 & 17.286 & 0.131 \\
\hline K4b & 90.20 & 89.37 & 87.40 & 78.11 & - & - & 1113.70 & 12.861 & 0.175 \\
\hline K5b & 95.01 & 90.82 & 88.79 & 80.64 & - & - & 1042.78 & 12.286 & 0.141 \\
\hline K6b & 91.58 & 90.22 & 88.04 & 79.42 & - & - & 1556.30 & 17.945 & - \\
\hline K7b & 92.04 & 88.94 & 90.25 & 80.26 & - & - & 962.00 & 11.032 & 0.106 \\
\hline K8b & 93.84 & 90.60 & 88.40 & 80.09 & 860.7 & 107.469 & - & - & - \\
\hline K9b & 93.08 & 89.42 & 88.53 & 79.16 & 704.5 & 89.001 & - & - & - \\
\hline K10b & 93.83 & 88.86 & 90.43 & 80.36 & 888.6 & 110.583 & - & - & - \\
\hline K11b & 86.99 & 73.38 & 90.10 & 66.11 & 472.6 & 71.486 & - & - & - \\
\hline K12b & 95.99 & 114.87 & 84.51 & 97.07 & 818.1 & 84.275 & - & - & - \\
\hline
\end{tabular}

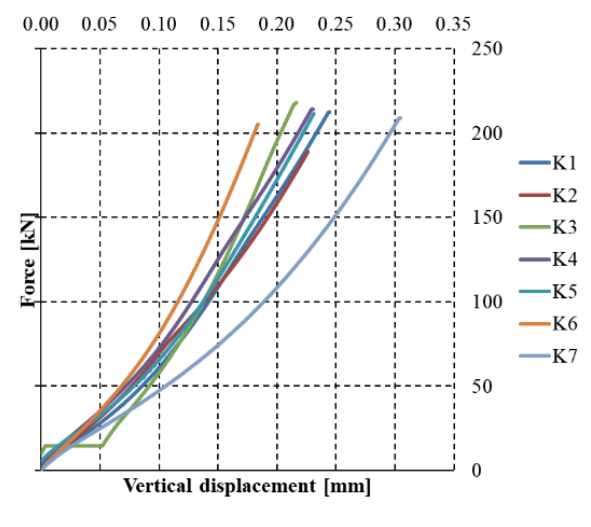

b)

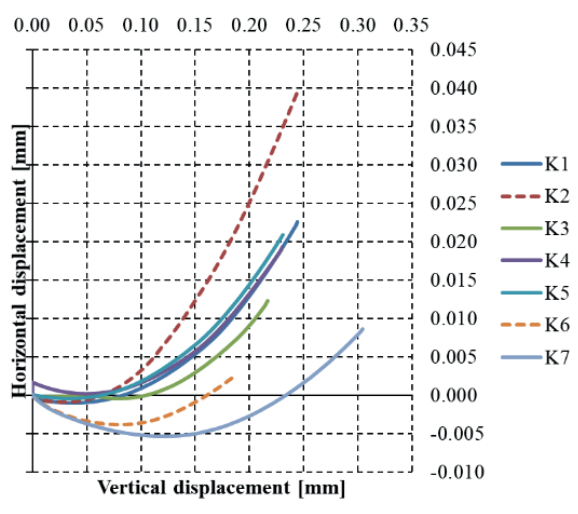

Fig. 5. Graphs of the uniaxial compression test for "Brenna" sandstone. a) the relationship of force and vertical displacement, b) the relationship of horizontal and vertical displacement. Source: own study 
The results in the diagrams marked with a dashed line were not taken into account because either they are too different from the others, or the test was carried out incorrectly. The graphs presented in fig. 3a, fig. 4a, and fig. 5a are the dependencies of the change of the compressive force on the vertical displacement (reading from the displacement transducer for "Braciszów" sandstone and porphyry, or average from vertical strain gauges for "Brenna" sandstone). Young's modulus $E$ was calculated from the following formula:

$$
E=\frac{h \cdot \lambda}{A}
$$

where $\lambda$ is the slope of the force dependence curve for vertical displacements in an area where there is a constant increase close to linear, assuming that in the sample during the test there is a uniaxial and homogeneous stress state and a homogeneous strain state. For example, $\lambda$ for "Brenna" sandstone is the ratio of force difference to displacement difference read in the range from $100 \mathrm{kN}$ to $200 \mathrm{kN}$ of force, because in this range there was a linear increase of displacement (see fig. 6a).

The graphs in fig. $3 \mathrm{~b}$, fig. $4 \mathrm{~b}$, and fig. $5 \mathrm{~b}$ are the dependencies between the horizontal displacement (recorded by the clip-on extensometer, or as the average of horizontal strain gauges), and vertical displacement, the same as when calculating Young's modulus. Poisson's ratio $v$ is determined as the slope of this curve. As before, only parts of the charts that are close to the linear function were considered.

The average value of the tensile strength $f_{\mathrm{c}}$ obtained from the tests for individual rock types was:

- "Braciszów" sandstone - 187.232 MPa with a standard deviation of $30.315 \mathrm{MPa}$, which is $16.19 \% f_{\mathrm{c}}$,

- "Zalas" porphyry - 210.338 MPa with a standard deviation of $38.056 \mathrm{MPa}$, which is $18.09 \% f_{\mathrm{c}}$,

- "Brenna" sandstone - 92.563 MPa with a standard deviation of 16.375 MPa, which is $17.69 \% f_{\mathrm{c}}$.

The average value of Young's modulus $E$ was obtained as follows:

- "Braciszów" sandstone - 15.745 GPa with a standard deviation of 4.757 GPa, which is $30.21 \% \mathrm{E}$,

- "Zalas" porphyry - $12.863 \mathrm{GPa}$ with a standard deviation of $3.312 \mathrm{GPa}$, which is $25.75 \% E$,

- "Brenna" sandstone - 13.727 GPa with a standard deviation of $2.741 \mathrm{GPa}$, which is $19.97 \%$ E

For the average value of Poisson's ratio $v$ results are presented below:

- "Braciszów" sandstone -0.203 with a standard deviation of 0.068 , which is $33.73 \% \mathrm{v}$,

- "Brenna" sandstone -0.148 with a standard deviation of 0.033 , which is $22.45 \% \mathrm{v}$.

Poisson's ratio for "Zalas" porphyry was not designated, because all results from tests were incorrect. The remaining results also lack in accuracy. The most accurate results are compressive strength results, but the error is still around $17 \%$. The reason for this is the large heterogeneity of the tested materials. Rocks of this type have a lot of local weakening in the form of linear inclusions. Examples of these inclusions are shown below. Fig. 6a shows a beam with local weakening and fig. $6 \mathrm{~b}$ shows the effect of the weakening on the Brazilian test. 
a)

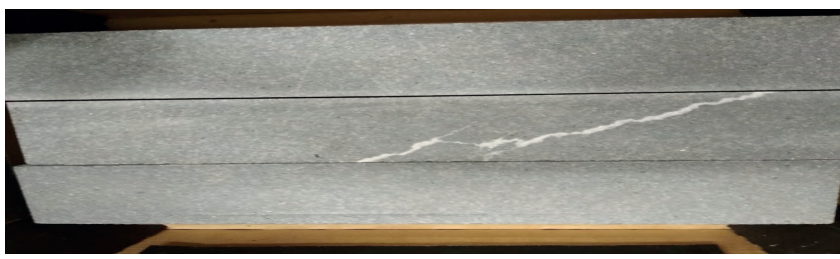

b)

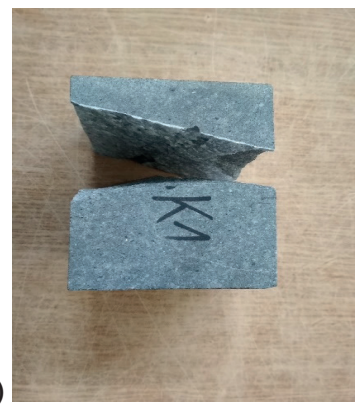

Fig. 6. a) Beam with local weakening, b) the effect of the weakening on the Brazilian test. Source: own study

The results for Young's modulus and Poisson's ratio are even more dispersed because they were affected by the displacement reading. However, there is a clear advantage of measurements with pairs of strain gauges over readings from one horizontal and vertical direction, besides with less accurate devices than strain gauges.

Apart from the heterogeneity of the material and the inaccuracy of the results from the devices for measuring displacements and strains, another reason for such differences may be the orthotropic of rocks. Sandstone is a sedimentary rock and is a layered material, which means that it has different parameters of compressive strength and deformability in different directions. Unfortunately, it was not possible to identify the stratification of materials based on the inspection of the available samples, as it would be required to know in which orientation the material was acquired from the rock block. It was also impossible to differentiate between the results which were compressed perpendicularly to the layers and the ones that were compressed parallel to the layers, because the layers in the cubic sample could arrange at any angle. For these reasons, the authors treat these materials as isotropic for future works.

\subsection{Beam bending test}

Tensile strength by use of a 3-point beam bending test was made only for "Brenna" sandstone. For the other two materials, tensile strength was calculated only using the method that involved splitting cubes. All available beams for these two materials were used to determine the stress intensity factor.

To determine the tensile strength, 4 beams (B1b-B4b) with cross-sectional dimensions of approximately $10 \times 10 \mathrm{~cm}$ and different support spacing were tested. The diagram for determining the tensile strength from this test is shown in fig. 7a. The test was performed on the MTS 319.25 testing machine.

a)

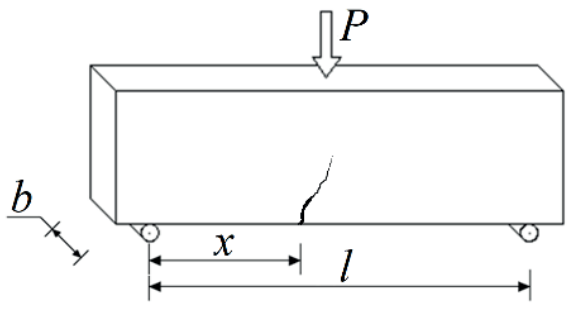

b)

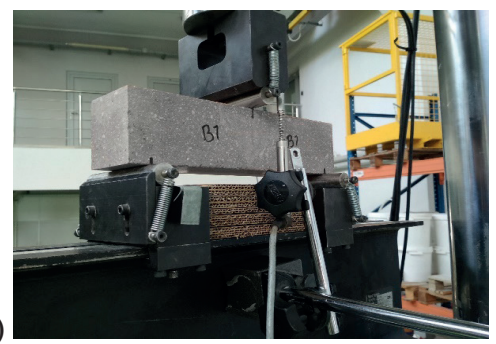

Fig. 7. 3-point beam bending test. a) scheme of the test, b) photo taken during the test. Source: own study 
Since the samples did not crack in the middle of the width, the value of the bending moment $M$ at the place where the crack appeared was calculated from the bellow equation:

$$
M=\frac{P \cdot l}{4} \cdot \frac{2 \cdot x}{l}=\frac{P \cdot x}{2}
$$

Where: $h$ - means the height of the sample, $b$ - means width, $l$ - the distance between supports, $x$ - the distance between crack initiation location, and the nearest support, $P$ - the maximum vertical force applied in the centre of the sample, read from the testing machine. The sample dimensions and calculation results are shown in Table 4. $A=a \times b-\mathrm{a}$ cross-section of the sample, $W=b h^{2} / 6-$ section modulus, $f_{\mathrm{t}}=M / W-$ tensile strength.

Table 4. Dimensions of the samples and results obtained in a 3-point beam bending test for "Brenna" sandstone. Source: own study

\begin{tabular}{llllllllll}
\hline Sample & $h$ & $b$ & $L$ & $x$ & $P$ & $A$ & $W$ & $M$ & $f_{\mathrm{t}}$ \\
& {$[\mathrm{mm}]$} & {$[\mathrm{mm}]$} & {$[\mathrm{mm}]$} & $\begin{array}{l}{[\mathrm{mm}]} \\
{[\mathrm{kN}]}\end{array}$ & $\begin{array}{l}{\left[\mathrm{cm}^{2}\right]} \\
{\left[\mathrm{cm}^{3}\right]}\end{array}$ & $\begin{array}{l}{[\mathrm{kNcm}]} \\
{[\mathrm{MPa}]}\end{array}$ \\
\hline B1b & 90.79 & 89.42 & 360 & 160 & 3.9099 & 81.18 & 122.84 & 31.279 & 2.546 \\
\hline B3b & 95.98 & 89.94 & 340 & 145 & 0.3946 & 86.32 & 138.08 & 2.861 & 0.207 \\
\hline B4b & 98.20 & 89.29 & 340 & 130 & 7.3348 & 87.68 & 143.50 & 47.676 & 3.322 \\
\hline
\end{tabular}

The above calculations show that the average tensile strength for "Brenna" sandstone was $3.112 \mathrm{MPa}$ with a standard deviation of $2.544 \mathrm{MPa}$, which is $81.78 \%$ of $f$. This dispersion is too large to take this result as correct.

\subsection{Determination of stress intensity factor}

Critical stress intensity factor in mode I, designated as $K_{\text {Ic }}$, is a material constant that determines the magnitude of the stress at the crack tip in the case of tensile loads working perpendicular to the crack surface. There are several methods for determining this factor [6]. The authors conducted a three-point bending test. This test was performed on specimens with a notch in the centre of its width and was executed on the MTS 319.25 testing machine. The test operation diagram is shown in fig. 8a. There were 6 samples of "Braciszów" sandstone (named N1c-N6c), 5 samples of "Zalas" porphyry (N1z-N5z) and 3 samples of "Brenna" sandstone (N1b-N3b). The samples were tested on the MTS 319.25 testing machine.

a)

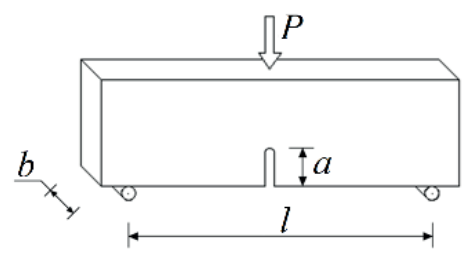

b)

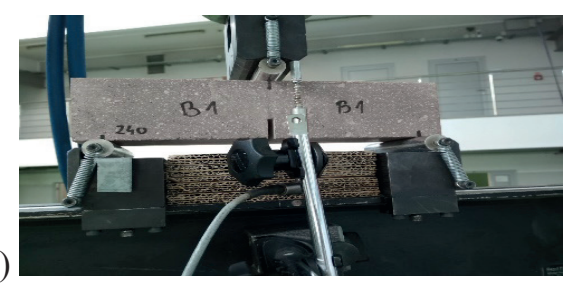

Fig. 8. 3-point beam bending test with a notch. a) scheme of the test, b) photo taken during the test. Source: own study 
There are many methods of calculating this stress intensity factor [7], [8]. The authors used the equation proposed by Brown and Srawley [9] because it allows any spacing of supports when other methods require spacings 4 times longer than the sample height.

$$
K_{I c}=\frac{3 P_{c} l \sqrt{\pi a}}{2 h^{2} b}\left[1.090-1.735 \frac{a}{h}+8.28\left(\frac{a}{h}\right)^{2}-14.18\left(\frac{a}{h}\right)^{3}+14.57\left(\frac{a}{h}\right)^{4}\right]
$$

In this equation and fig. $8 \mathrm{a} P_{\mathrm{c}}$ is the destructive force, $l$ - the spacing of supports, $a$ - length of the notch, $h$ - the height of the beam, $b$ - the width of the beam. The results obtained from the test are presented in Table 5, Table 6, and Table 7.

Table 5. Dimensions of the samples and results obtained in a 3-point beam bending test with a notch for "Braciszów" sandstone. Source: own study

\begin{tabular}{lllllll}
\hline Sample & $\begin{array}{l}h \\
{[\mathrm{~mm}]}\end{array}$ & $\begin{array}{l}b \\
{[\mathrm{~mm}]}\end{array}$ & $\begin{array}{l}a \\
{[\mathrm{~mm}]}\end{array}$ & $\begin{array}{l}l \\
{[\mathrm{~mm}]}\end{array}$ & $\begin{array}{l}P \\
{[\mathrm{kN}]}\end{array}$ & $\begin{array}{l}K_{\text {Ic }} \\
{\left[\mathrm{N} / \mathrm{mm}^{3 / 2}\right]}\end{array}$ \\
\hline N1c & 70.44 & 69.99 & 25 & 300 & 6.041 & 76.618 \\
\hline N2c & 69.55 & 70.17 & 25 & 300 & 4.613 & 60.182 \\
\hline N3c & 69.79 & 69.87 & 25 & 300 & 5.362 & 69.673 \\
\hline N4c & 70.45 & 70.88 & 25 & 240 & 7.249 & 72.597 \\
\hline N5c & 68.63 & 69.67 & 25 & 240 & 6.299 & 68.437 \\
\hline N6c & 70.18 & 70.28 & 25 & 240 & 6.629 & 67.596 \\
\hline
\end{tabular}

Table 6. Dimensions of the samples and results obtained in a 3-point beam bending test with a notch for "Zalas" porphyry. Source: own study

\begin{tabular}{lllllll}
\hline Sample & $h$ & $b$ & $a$ & $l$ & $P$ & $K_{\text {Ic }}$ \\
& {$[\mathrm{mm}]$} & {$[\mathrm{mm}]$} & {$[\mathrm{mm}]$} & {$[\mathrm{mm}]$} & {$[\mathrm{kN}]$} & {$\left[\mathrm{N} / \mathrm{mm}^{3 / 2}\right]$} \\
\hline $\mathrm{N} 1 \mathrm{z}$ & 70.06 & 70.20 & 25 & 300 & 4.633 & 59.524 \\
\hline $\mathrm{N} 2 \mathrm{z}$ & 69.15 & 70.22 & 25 & 300 & 4.403 & 58.888 \\
\hline $\mathrm{N} 3 \mathrm{z}$ & 69.75 & 69.91 & 25 & 300 & 3.764 & 49.087 \\
\hline $\mathrm{N} 4 \mathrm{z}$ & 69.86 & 69.71 & 25 & 300 & 5.490 & 71.017 \\
\hline $\mathrm{N} 5 \mathrm{z}$ & 69.95 & 69.88 & 25 & 300 & 5.578 & 72.225 \\
\hline
\end{tabular}

Table 7. Dimensions of the samples and results obtained in a 3-point beam bending test with a notch for "Brenna" sandstone. Source: own study

\begin{tabular}{lllllll}
\hline Sample & $h$ & $b$ & $a$ & $l$ & $P$ & $K_{\text {Ic }}$ \\
& {$[\mathrm{mm}]$} & {$[\mathrm{mm}]$} & {$[\mathrm{mm}]$} & {$[\mathrm{mm}]$} & $\begin{array}{l}P \\
{[\mathrm{kN}]}\end{array}$ & {$\left[\mathrm{N} / \mathrm{mm}^{3 / 2}\right]$} \\
\hline N1b & 93.70 & 90.22 & 25 & 320 & 4.211 & 22.963 \\
\hline N2b & 87.48 & 120.15 & 25 & 400 & 4.275 & 25.464 \\
\hline N3b & 88.17 & 120.94 & 25 & 240 & 8.179 & 28.538 \\
\hline
\end{tabular}

From the above results, the average values of stress intensity factors were determined:

- "Braciszów" sandstone $-69.184 \mathrm{~N} / \mathrm{mm}^{3 / 2}$ with a standard deviation of $5.500 \mathrm{~N} / \mathrm{mm}^{3 / 2}$, which is $7.95 \% K_{\mathrm{Ic}}$,

- “Zalas" porphyry $-55.833 \mathrm{~N} / \mathrm{mm}^{3 / 2}$ with a standard deviation of $5.851 \mathrm{~N} / \mathrm{mm}^{3 / 2}$, which is $10.48 \% K_{\text {Ic }}$,

- "Brenna" sandstone $-25.655 \mathrm{~N} / \mathrm{mm}^{3 / 2}$ with a standard deviation of $2.792 \mathrm{~N} / \mathrm{mm}^{3 / 2}$, which is $10.88 \% K_{\mathrm{Ic}}$.

Also, the authors determined the critical strain energy release rate $G_{\mathrm{Ic}}=K_{\mathrm{Ic}}{ }^{2} / E$ [6], which is $303.995 \mathrm{~N} / \mathrm{m}$ for "Braciszów" sandstone, $242.344 \mathrm{~N} / \mathrm{m}$ for "Zalas" porphyry and $47.946 \mathrm{~N} / \mathrm{m}$ for "Brenna" sandstone. 


\subsection{Tensile during splitting test}

Due to the lack of a sufficient number of beams, it was decided to use most of the beams for three-point bending test of beams with notches, and determine the tensile strength using the quasi-Brazilian method. 7 cubic samples $7 \times 7 \times 7 \mathrm{~cm}$ of "Braciszów" sandstone (T1c-T7c), 7 samples of "Zalas" porphyry (T1z-T7z), and 6 samples $9 \times 9 \times 9 \mathrm{~cm}$ of "Brenna" sandstone (T1b-T6b) were used. Also, the authors used unusual $7 \times 7 \mathrm{~cm}$ samples with much longer width (about $14 \mathrm{~cm}$ to $17 \mathrm{~cm}$ ), which below is referred to as beams. The authors wanted to check if beams could also be used as samples for the Brazilian test. 12 beam samples of "Braciszów" sandstone (T8c-T19c) and 10 samples of "Zalas" porphyry (T8z-T17z) were tested. The beams were obtained from halves of destroyed beams used in 3-point bending tests. No "Brenna" sandstone beams were tested. The samples were loaded on a WalterBai testing machine.

For the purpose that samples were cuboids, the calculation method described in previous authors' paper [10] was used. Typically, cylindrical samples are tested using this method, but in this case, cuboid samples was the only option. Because there is no analytical solution when compressing a cuboid with two balancing linear loads, as in the case of a cylinder, the stress field was numerically determined using FEM. The authors wanted to find the dependence between the tensile stresses that appear in the centre of the sample and the value of the force applied to the sample. This ratio will be named as $\chi$ and is determined for $1 \mathrm{~cm}$ of load length. Computer simulations showed that $\chi$ equals 0.069 for $9 \times 9 \times 9 \mathrm{~cm}$ samples, 0.088 for $7 \times 7 \times 7 \mathrm{~cm}$ samples, and about 0.070 for beam samples. It turns out that this ratio changes significantly when the width $a$ is less than 1.5 of $h$. When this width is greater than 1.5 , then this ratio does not change much, so the authors decided to leave the value of 0.070 for all beams. The scheme of this task is shown in fig. $9 \mathrm{a}$.

a)

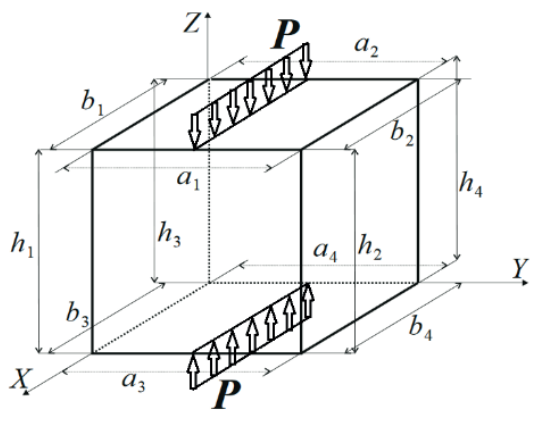

b)

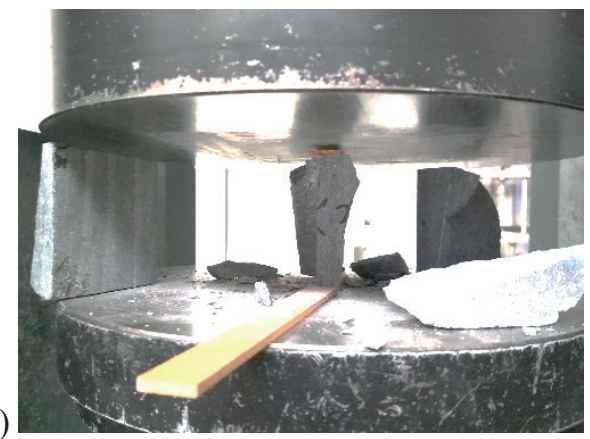

Fig. 9. Splitting test performed on cuboid samples. a) scheme of the test, b) photo was taken after one of the tests. Source: own study

Also, it was assumed that the value of tensile strength is greater than the determined maximum value of tensile stresses because in the middle of the sample there are also compressive stresses that affect the strength of the material. The ratio of tensile stress to tensile strength is marked as $\rho$, and for the Ottosen-Podgórski criterion, it is calculated as follows:

$$
\rho=\frac{\sigma_{\max }}{f_{t}}=\frac{\sqrt{1+4 \cdot \gamma^{2}}-1}{2 \cdot \gamma^{2}}, \text { where } \gamma=\frac{\kappa}{\eta}
$$

$\kappa$ is the ratio between vertical (compressive) stresses and horizontal (tensile) stresses in the middle of the sample which for $9 \times 9 \times 9 \mathrm{~cm}$ samples is 3.263 , for $7 \times 7 \times 7 \mathrm{~cm}$ samples is 
3.241 and for beam samples is 2.687 . This value also changes insignificantly when the width of the sample is greater than 1.5 of the height.

$\eta$ is the ratio of the compressive strength to tensile strength $f_{\mathrm{c}} / f_{\mathrm{t}}$, and it was calculated by iterations. After one calculation of the tensile strength from this method, the ratio $\eta$ changed and is substituted to the formula up to the moment where this ratio does not change. The tensile strength $f_{\mathrm{t}}$ was calculated from the following formula:

$$
f_{t}=\frac{\sigma_{\max }}{\rho}, \text { where } \sigma_{\max }=q \cdot \chi, q=\frac{P}{b}
$$

$\sigma_{\max }$ are maximum tensile stresses that occur in the middle of the sample, $q$ is the load obtained from the machine, distributed on the depth of the sample. The results from all calculations are presented in Table 8, Table 9, and Table 10.

Table 8. Dimensions of the samples and results obtained in the splitting test performed on cuboid samples for "Braciszów" sandstone. Source: own study

\begin{tabular}{|c|c|c|c|c|c|c|c|}
\hline Sample & $\begin{array}{l}h \\
{[\mathrm{~mm}]}\end{array}$ & $\begin{array}{l}a \\
{[\mathrm{~mm}]}\end{array}$ & $\begin{array}{l}b \\
{[\mathrm{~mm}]}\end{array}$ & $\begin{array}{l}P \\
{[\mathrm{kN}]}\end{array}$ & $\begin{array}{l}q \\
{[\mathrm{kN} / \mathrm{m}]}\end{array}$ & $\begin{array}{l}\sigma_{\max } \\
{[\mathrm{MPa}]}\end{array}$ & $\begin{array}{l}f_{\mathrm{t}} \\
{[\mathrm{MPa}]}\end{array}$ \\
\hline T1c & 68.20 & 69.92 & 69.75 & 98.7 & 1415.104 & 12.474 & 12.687 \\
\hline $\mathrm{T} 2 \mathrm{c}$ & 69.71 & 69.69 & 69.88 & 153.4 & 2195.113 & 19.349 & 19.680 \\
\hline $\mathrm{T} 3 \mathrm{c}$ & 69.44 & 70.17 & 63.27 & 155.8 & 2462.462 & 21.706 & 22.077 \\
\hline T4c & 69.72 & 69.80 & 70.13 & 82.3 & 1173.577 & 10.345 & 10.522 \\
\hline $\mathrm{T} 5 \mathrm{c}$ & 69.70 & 69.85 & 69.65 & 55.7 & 799.770 & 7.050 & 7.170 \\
\hline T6c & 69.65 & 69.73 & 69.52 & 58.7 & 844.392 & 7.443 & 7.570 \\
\hline $\mathrm{T} 7 \mathrm{c}$ & 69.58 & 69.65 & 69.54 & 40.3 & 579.502 & 5.108 & 5.195 \\
\hline T8c & 70.77 & 173.50 & 70.06 & 77.7 & 1109.010 & 7.772 & 7.845 \\
\hline T9c & 70.49 & 174.50 & 70.11 & 80.1 & 1142.450 & 8.006 & 8.081 \\
\hline T10c & 69.58 & 175.50 & 70.48 & 88.5 & 1255.675 & 8.799 & 8.882 \\
\hline T11c & 69.53 & 176.50 & 69.87 & 77.5 & 1109.242 & 7.773 & 7.846 \\
\hline $\mathrm{T} 12 \mathrm{c}$ & 69.77 & 177.50 & 70.01 & 87.7 & 1252.723 & 8.779 & 8.861 \\
\hline $\mathrm{T} 13 \mathrm{c}$ & 69.77 & 178.50 & 69.79 & 57.2 & 819.572 & 5.743 & 5.797 \\
\hline T14c & 70.58 & 137.00 & 70.69 & 41.1 & 581.432 & 4.075 & 4.113 \\
\hline $\mathrm{T} 15 \mathrm{c}$ & 70.53 & 138.00 & 70.81 & 70.0 & 988.526 & 6.927 & 6.993 \\
\hline T16c & 68.74 & 139.00 & 69.81 & 31.4 & 449.792 & 3.152 & 3.182 \\
\hline $\mathrm{T} 17 \mathrm{c}$ & 68.51 & 140.00 & 69.58 & 57.1 & 820.697 & 5.751 & 5.805 \\
\hline $\mathrm{T} 18 \mathrm{c}$ & 70.24 & 141.00 & 70.32 & 62.3 & 885.981 & 6.209 & 6.267 \\
\hline T19c & 70.10 & 142.00 & 70.27 & 77.9 & 1108.660 & 7.769 & 7.842 \\
\hline
\end{tabular}

The first three tests of "Braciszów" sandstone (T1c-T3c) were performed using a $1.5 \mathrm{~cm}$ wide fiberboard pad. It turns out that this width is too broad because samples were splitting in two planes, not in one, which can be seen in fig. 9. This width is one-fifth of the sample width, which caused that the load was too wide and worked at two points, not as a concentrated load. These results were therefore omitted because the destructive force was much higher than the others. All other tests were performed using the $0.7 \mathrm{~cm}$ pad. 
Table 9. Dimensions of the samples and results obtained in the splitting test performed on cuboid samples for "Zalas" porphyry. Source: own study

\begin{tabular}{llllllll}
\hline Sample & $\begin{array}{l}h \\
{[\mathrm{~mm}]}\end{array}$ & $\begin{array}{l}a \\
{[\mathrm{~mm}]}\end{array}$ & $\begin{array}{l}P \\
{[\mathrm{~mm}]}\end{array}$ & $\begin{array}{l}P \\
{[\mathrm{kN}]}\end{array}$ & $\begin{array}{l}q \\
{[\mathrm{kN} / \mathrm{m}]}\end{array}$ & $\begin{array}{l}\sigma_{\max } \\
{[\mathrm{MPa}]}\end{array}$ & $\begin{array}{l}f_{\mathrm{t}} \\
{[\mathrm{MPa}]}\end{array}$ \\
\hline $\mathrm{T} 1 \mathrm{z}$ & 70.52 & 69.50 & 70.24 & 102.0 & 1452.216 & 12.801 & 13.061 \\
\hline $\mathrm{T} 2 \mathrm{z}$ & 70.21 & 70.10 & 69.89 & 72.8 & 1041.674 & 9.182 & 9.368 \\
\hline $\mathrm{T} 3 \mathrm{z}$ & 68.84 & 70.39 & 70.31 & 59.0 & 839.201 & 7.397 & 7.547 \\
\hline $\mathrm{T} 4 \mathrm{z}$ & 70.14 & 70.38 & 72.92 & 64.8 & 888.645 & 7.833 & 7.992 \\
\hline $\mathrm{T} 5 \mathrm{z}$ & 69.92 & 70.21 & 69.58 & 54.5 & 783.243 & 6.904 & 7.044 \\
\hline $\mathrm{T} 6 \mathrm{z}$ & 70.12 & 69.99 & 70.02 & 75.2 & 1073.941 & 9.467 & 9.659 \\
\hline $\mathrm{T} 7 \mathrm{z}$ & 70.17 & 70.35 & 69.89 & 83.0 & 1187.665 & 10.469 & 10.681 \\
\hline $\mathrm{T} 8 \mathrm{z}$ & 70.09 & 173.50 & 70.19 & 67.1 & 956.045 & 6.700 & 6.760 \\
\hline $\mathrm{T} 9 \mathrm{z}$ & 70.31 & 173.50 & 70.24 & 90.0 & 1281.276 & 8.979 & 9.060 \\
\hline $\mathrm{T} 10 \mathrm{z}$ & 69.47 & 173.50 & 70.13 & 44.9 & 640.217 & 4.486 & 4.527 \\
\hline $\mathrm{T} 11 \mathrm{z}$ & 69.69 & 173.50 & 70.16 & 56.8 & 809.636 & 5.674 & 5.725 \\
\hline $\mathrm{T} 12 \mathrm{z}$ & 69.86 & 173.50 & 70.19 & 73.7 & 1050.082 & 7.359 & 7.425 \\
\hline $\mathrm{T} 13 \mathrm{z}$ & 69.83 & 173.50 & 70.10 & 64.3 & 917.326 & 6.428 & 6.486 \\
\hline $\mathrm{T} 14 \mathrm{z}$ & 69.92 & 137.00 & 69.52 & 77.9 & 1120.541 & 7.852 & 7.923 \\
\hline $\mathrm{T} 15 \mathrm{z}$ & 70.20 & 138.00 & 69.63 & 80.7 & 1159.066 & 8.122 & 8.196 \\
\hline $\mathrm{T} 16 \mathrm{z}$ & 70.03 & 139.00 & 69.91 & 93.6 & 1338.960 & 9.383 & 9.467 \\
\hline $\mathrm{T} 17 \mathrm{z}$ & 70.07 & 140.00 & 70.08 & 89.3 & 1274.213 & 8.929 & 9.010 \\
\hline
\end{tabular}

Table 10. Dimensions of the samples and results obtained in the splitting test performed on cuboid samples for "Brenna" sandstone. Source: own study

\begin{tabular}{llllllll}
\hline Sample & $\begin{array}{l}h \\
{[\mathrm{~mm}]}\end{array}$ & $a$ & $b$ & $P$ & $q$ & $\sigma_{\max }$ & $f_{\mathrm{t}}$ \\
& {$[\mathrm{mm}]$} & {$[\mathrm{mm}]$} & {$[\mathrm{kN}]$} & $\begin{array}{l}q \\
{[\mathrm{kN} / \mathrm{m}]}\end{array}$ & {$[\mathrm{MPa}]$} & {$[\mathrm{MPa}]$} \\
\hline T1b & 95.22 & 106.96 & 88.80 & 44.8 & 504.505 & 3.497 & 3.541 \\
\hline T2b & 95.18 & 107.46 & 88.82 & 45.9 & 516.776 & 3.582 & 3.627 \\
\hline T3b & 95.21 & 105.96 & 90.61 & 29.3 & 323.364 & 2.241 & 2.270 \\
\hline T4b & 94.92 & 107.63 & 88.36 & 51.1 & 578.332 & 4.009 & 4.059 \\
\hline T5b & 90.02 & 96.56 & 83.23 & 30.6 & 367.656 & 2.548 & 2.581 \\
\hline T6b & 94.26 & 105.03 & 90.75 & 41.1 & 452.905 & 3.139 & 3.179 \\
\hline
\end{tabular}

From the above results, the average values of tensile stresses using solely cubic samples are presented below:

- "Braciszów" sandstone - 7.614 MPa with a standard deviation of 2.199 MPa, which is $28.87 \% f_{\mathrm{t}}$,

- "Zalas" porphyry - 9.336 MPa with a standard deviation of $2.084 \mathrm{MPa}$, which is $22.32 \% f_{\mathrm{t}}$,

- "Brenna" sandstone - 3.209 MPa with a standard deviation of 0.676 MPa, which is $21.07 \% f_{\mathrm{t}}$.

The result for "Brenna" sandstone is almost the same as obtained from the 3-point bending test, which was $3.111 \mathrm{MPa}$. This proves that results obtained by this quasi-Brazilian method are correct, but the spread of results is extensive. The next important thing is the results from splitting the beam samples.

- "Braciszów" sandstone - 6.793 MPa with a standard deviation of $1.813 \mathrm{MPa}$, which is $26.68 \% f_{\mathrm{t}}$, 
- "Zalas" porphyry - 7.458 MPa with a standard deviation of $1.537 \mathrm{MPa}$, which is $20.61 \% f_{\mathrm{t}}$.

These results are $10-20 \%$ lower than obtained from cubes, which means that they probably cannot be considered correct.

\section{Summary}

The determination of material parameters and verification of the physical and numerical model is an integral part of a correctly performed computer simulation. The research described in the article is an example of the solution to an important problem of determining the mechanical properties of the modelled material. The results described in the paper are presented in Table 11.

Table 11. Summary of all determined results. Source: own study

\begin{tabular}{lllllll}
\hline Material & $\begin{array}{l}f_{\mathrm{c}} \\
{[\mathrm{MPa}]}\end{array}$ & $\begin{array}{l}f_{\mathrm{t}} \\
{[\mathrm{MPa}]}\end{array}$ & $\begin{array}{l}E \\
{[\mathrm{GPa}]}\end{array}$ & $\begin{array}{l}v \\
{[-]}\end{array}$ & $\begin{array}{l}K_{\mathrm{Ic}} \\
{\left[\mathrm{N} / \mathrm{mm}^{3 / 2}\right]}\end{array}$ & $\begin{array}{l}G_{\mathrm{Ic}} \\
{[\mathrm{N} / \mathrm{m}]}\end{array}$ \\
\hline $\begin{array}{l}\text { "Braciszów" } \\
\text { sandstone }\end{array}$ & 187.232 & 7.614 & 15.745 & 0.203 & 69.184 & 303.995 \\
\hline $\begin{array}{l}\text { "Zalas" } \\
\text { porphyry }\end{array}$ & 210.338 & 9.336 & 12.863 & - & 55.833 & 242.344 \\
\hline $\begin{array}{l}\text { "Brenna" } \\
\text { sandstone }\end{array}$ & 92.562 & 3.209 & 13.727 & 0.148 & 25.655 & 47.946 \\
\hline
\end{tabular}

"Braciszów" sandstone and "Zalas" porphyry turned out to be materials with the highest parameters. "Brenna" sandstone is a weaker material, with lower fracture energy and lower tensile and compressive strength, even though it did not have any local weakening, unlike the "Braciszów" sandstone. Porphyry turned out to be the most durable material, which was to be expected. In addition to obtaining material parameters based on tests, several conclusions were made:

- Sandstone and porphyry are very heterogeneous materials with local weaknesses, which leads to a large spread of results,

- The uniaxial compression of cubes using a pair of strain gauges allows for much more accurate results than when using a single reading from external devices,

- Author's method of calculating tensile strength during splitting gives satisfying results,

- The use of beams in the above method is not recommended,

- When testing small samples using the Brazilian method, it is advisable to use a narrow pad (not larger than $10 \%$ of the sample width).

The obtained material parameters will be used to verify the authors' method of crack direction prediction in the Abaqus FEA system. The authors hope that the results presented in work will also be useful for other researchers that use rocks in their studies.

\section{References}

[1] Gontarz J. et al., "Comparison between numerical analysis and actual results for a pull-out test," Engineering Transactions, vol. 67, no. 3, (2019), pp. 311-331. https://doi.org/10.24423/ EngTrans.1005.20190815

[2] Gontarz J. et al., "Podsumowanie badań laboratoryjnych piaskowca pod kątem analizy wyrywania kotwy," Budownictwo i Architektura, vol. 16, no. 3, (2017), pp. 113-123. https://doi.org/10.24358/ Bud-Arch_17_163_11 
[3] Tomiczek K., "O różnicach w zachowaniu się skał w warunkach jednoosiowego rozciągania i ściskania," Górnictwo i Geoinżynieria, vol. 3, no. 1, (2007), pp. 543-554.

[4] Łukasiak D., "Zmienność wytrzymałościowa piaskowców godulskich z Brennej w warunkach jednoosiowego ściskania," Górnictwo i Geoinżynieria, vol. R. 34, z. 2, (2010), pp. 435-441.

[5] Kłopotowska A., "Resistance of szydłowiecki sandstone to salt crystallization in terms of structural strengthening," Górnictwo i Geoinżynieria, vol. 35, no. 2, (2011), pp. 341-347.

[6] Mier J. G. M. van, Fracture processes of concrete. CRC Press, 1996.

[7] Bower A.F., Applied mechanics of solids. CRC Press, 2010. Available: https://www.crcpress.com/ Applied-Mechanics-of-Solids/Bower/p/book/9781439802472 [Access: 15 Jan 2020]

[8] Elices M. et al., "The cohesive zone model: advantages, limitations and challenges," Engineering fracture mechanics, vol. 69, no. 2, (2002), pp. 137-163. https://doi.org/10.1016/ S0013-7944(01)00083-2

[9] Brown W. F. and Srawley J.E., Plane Strain Crack Toughness Testing of High Strength Metallic Materials. Philadelphia: ASTM International, 1966. https://doi.org/10.1520/STP410-EB Available: http://www.astm.org/doiLink.cgi?STP410-EB [Access: 15 Jan 2020]

[10] Gontarz J. and Podgórski J., "Explanation of the mechanism of destruction of the cylindrical sample in the Brazilian test," in Advances in Mechanics : Theoretical, Computational and Interdisciplinary Issues, Kleiber M. et al. Eds. Gdańsk: Boca Raton, 2016, pp. 479-483. 